\title{
The Perspectives of a Global Information Technology Outsourcing Model
}

\author{
Muhammad Yunus Amar ${ }^{1}$, Julius Jillbert ${ }^{2}$ \\ Departemen of Management, Faculty of Economic and Business- Hasanuddin \\ University ${ }^{1,2}$ \\ myunmar@gmail.com ${ }^{1}$,julius.jillbert@gmail.com²
}

\begin{abstract}
This paper discusses some major contributors to offshore Information Technology (IT) outsourcing risks and examines some key risk mitigation strategies. Offshore IT outsourcing risks emanating from service provider IT capabilities in terms of their communication networks and human resource assets quality and cultural climate are examined using literature drawn from the areas of resource-based theory and culture theory particulary the transaction cost economies. The role of service recipient risk mitigation strategies including strong contract construction and intelligence gathering in moderating the impact of risk drivers on offshore outsourcing risks is discussed. The role of some key service provider policies and practices including policies regarding employees' acceptable use of client information, practices that seek to increase employee retention, and policies that do not allow employees to work on projects for multiple corporations that are competitors with each other in reducing offshore outsourcing risk is also examined.
\end{abstract}

Keywords: service recipient, service provider,global IT, outsourcing,risk

\section{Introduction}

TechNavio's analysts forecast the Global IT Outsourcing market to grow at a CAGR of 5.71 percent over the period 2013-2018 [1]. And along with this growth, a drive to achieve costeffective operations to tackle high attrition rate remains as the company tries to save billion through global IT outsourcing to countries such as Indonesia, India, South Africa, and the former Soviet Union where skilled IT workers are plentiful and inexpensive [2]. Most of these outsourcing service providers produce software services, such as debugging existing code, and perform low-level software development tasks [3].

While most of these activities would fall under the category of "support" functions, with low strategic impact, there are several firms who are more closely enmeshed with their outsourcing service provider, and whose relationship with said service provider has a high impact on the success of the service recipient firm itself [4]. This access to skilled labor forces, coupled with the cost savings promised by service providers in developing countries, makes offshore outsourcing very attractive to US corporations. Particularly due to the recent recession, 
corporations are attempting to cut costs wherever they can, with IT spending being near the top of the list.

There already exists a wide body of literature analyzing factors that influence a company's decision to outsource [5];[3];[6] factors that affect success in outsourcing [7];[8];[9], as well as issues of trust between service providers and service recipients in outsourcing [10]. However, the existing body of literature fails to address the unique aspects of global IT outsourcing that make its needs different from other types of outsourcing relationships.

Specifically, offshore IT outsourcing (referred as offshore outsourcing from this point forward) has several characteristics that impact the risks of these transactions. Global outsourcing involves corporations whose IT capabilities differ vastly from those normally present in the United States, as well as employees whose culture and value systems may be quite dissimilar to those held by employees in the United States [11]. The costs involved in counteracting these issues through methods such as strong contracts and pre- emptive intelligence gathering need to be taken into account, since cost may prove to be a prohibitive factor for effective IT outsourcing [5].

The purpose of this paper is to bring together outsourcing variables from the literature in the context of outsourcing risk. The risks inherent in these variables are outlined and analyzed using resource-based theory, culture theory, and IT capabilities literature. The determinants discussed here include characteristics of the service provider organization.

The comprehensive global IT outsourcing model put forth in this paper (Fig. 1) should serve as a reference point for analysis of current global IT outsourcing efforts, as well as a basis for planning future global IT outsourcing efforts. The following sections outlines the research model based on theory and describes the constructs involved and the relationships they form within the model. Finally, the last section offers some concluding remarks and directions for future research.

\section{Method}

This research seeks to find evidence that the risks of offshore outsourcing are determined by the several variables inherent to the service provider and the service provider's host nation. These variables include the service provider's IT capabilities and the service provider's cultural climate.

\section{Result}

This section defines and ties to literature the constructs involved in the research model (Fig.1). The constructs included in this research model are Offshore Outsourcing Risk, Service Provider IT Capabilities, Service Provider Culture Climate, existing Service Recipient Risk Mitigation Strategies, and existing Service Provider risk mitigation strategies. 


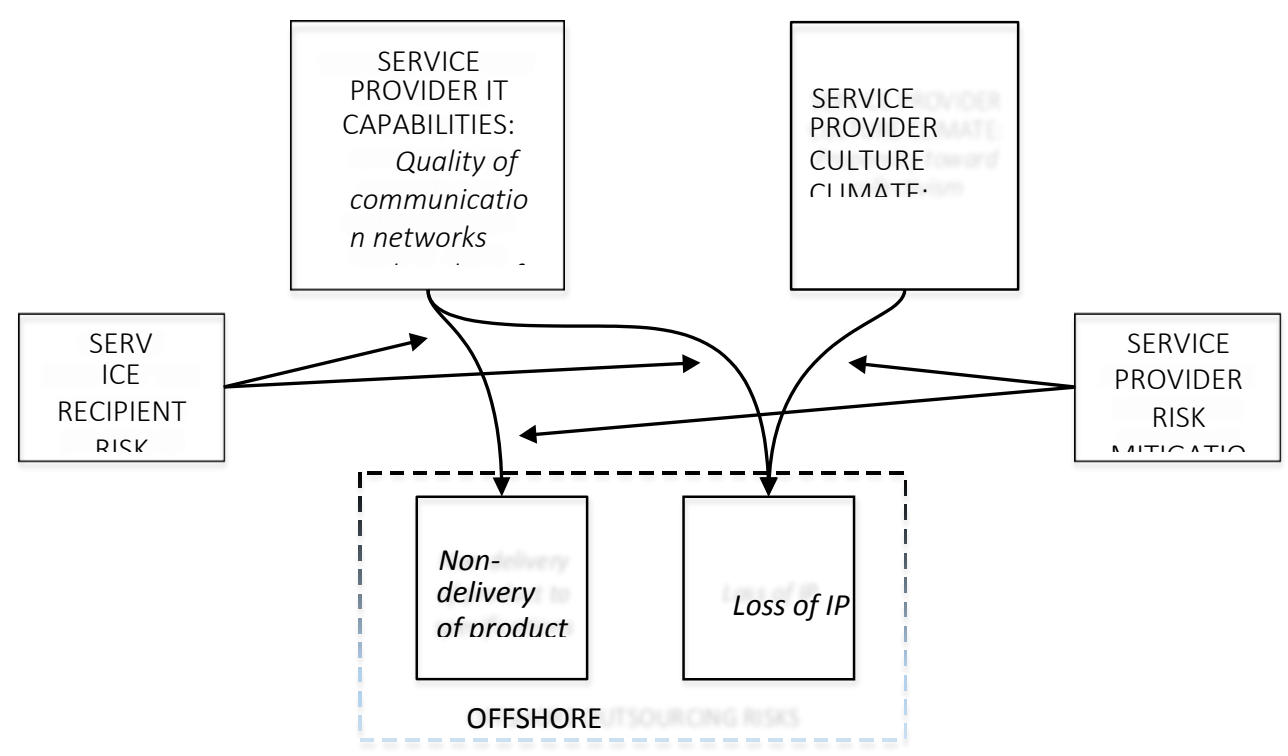

Fig. 1. Global IT Outsourcing Model

\section{Offshore outsourcing risk}

There are several possible conceptualizations and definitions of the notion of risk. Risk as a function of the expected loss from undertaking a certain venture and the probability that said loss will occur[12]. furthers this notion of risk by adding an actor's expected utility from undertaking a venture to the risk equation[13]. Thus, risk here is measured not only by the probability and value of loss, but by the value of what is to be gained. In this case, however, we define offshore outsourcing risk as an expected loss in offshore outsourcing contracts, following the perspective used in the context of IT outsourcing in [12]; that is, taking into consideration the magnitude of loss from an undesirable situation and the probability of occurrence of such loss. In the diagram above, two types of offshore outsourcing risk are mentioned. "Non-delivery of product to specifications" refers to a product that does not meet the specifications of the original contract, is flawed, or otherwise unacceptable to the service recipient[12]. "Loss of Intelectual Property" (Loss of IP) includes the sharing of a service recipient's intellectual property, such as source code and personal company information, with other entities that do not have the right to access it [12].

Fig. 2 shows a brief graphical overview of which types of risk correspond to which risk determinants from previous literature. The following sections identify several determinants and moderators of risk in offshore outsourcing and their relationship to the risk inherent in offshore outsourcing. 


\begin{tabular}{|c|c|c|}
\hline \multirow[b]{2}{*}{ High } & \multicolumn{2}{|c|}{$\begin{array}{l}\text { LEVEL OF IT CAPABILITIES } \\
\text { Low }\end{array}$} \\
\hline & $\begin{array}{l}\text { Outsource at your own Risk } \\
\text { - High Risk for Loss of IP due to } \\
\text { high Collectivism } \\
\text { - High Risk for non-delivery of } \\
\text { product to specifications and } \\
\text { Loss of IP due to low IT } \\
\text { C apabilities }\end{array}$ & $\begin{array}{l}\text { Quality without Safety } \\
\text { - Low risk for non-delivery of } \\
\text { product to specifications and } \\
\text { Loss of IP due to high IT } \\
\text { Capabilities } \\
\text { - High risk for Loss of IP due to high } \\
\text { Collectivism }\end{array}$ \\
\hline Low & $\begin{array}{l}\text { Safety without Quality } \\
\text { - High risk for non-delivery of } \\
\text { ct to specifications and Loss } \\
\text { of IP due to low IT } \\
\text { Capabilities } \\
\text { - Low risk for Loss of IP due to low } \\
\text { Collectivism }\end{array}$ & $\begin{array}{l}\text { Ideal Outsourcing Environment } \\
\text { - Low risk for non-delivery of } \\
\text { product to specifications and } \\
\text { Loss of IP due to high IT } \\
\text { Capabilities } \\
\text { - Low risk for Loss of IP due to low } \\
\text { Collectivism }\end{array}$ \\
\hline
\end{tabular}

Fig. 2. Four Types of Risk Situations

\section{Discussion}

\subsection{Service provider it capabilities}

The Service Provider IT Capabilities are defined in this research as the quality of reliable, secure communications and quality of human resource assets to the offshore outsourcing service provider. Since infrastructure can vary from service provider to service provider, this variable refers to infrastructure on a corporation level. An organization is comprised of its various tangible and intangible resources[14]. The resource-based view suggests that the usefulness, quality, and uniqueness of these resources together make up the value of the corporation. This is not to say that any resource that the firm possesses automatically gives it a competitive advantage.

RBV describes competitive advantage-generating resources as those which are not easily immitatable, substituted for, or transferred to another party [15]. we see that the resource -based theory, when taken in the context of information systems research, identifies infrastructure variables such as communications networks and human resource assets as resources important to the success of an information systems operation. Firms with capabilities specifically in the IT area have an inherent advantage based on their ability to better acquire, develop, implement and manage IT resources[9].

Taking the above information concerning the resource-based theory and information systems capabilities into consideration, the conclusion can be made that the quality of infrastructure resources of the service recipient can either increase or decrease the propensity for loss on the side of the service provider. Since this will also mean a loss for the service recipient, any variables that may increase the chance for loss will increase risk as it is defined in [12].

Thus, we arrive at the following:

Proposition 1a: The quality of the service provider's physical IT capabilities, such as communication networks, contributes to the risk associated with an offshore outsourcing relationship. 
In the context of this research, the overall quality of human resource assets of the service provider are also being classified as service provider infrastructure variables. Human capital is important resources to the firm[16]. The overall quality of human resource assets, for the purpose of this research, will consist of the knowledge and skills of the Service Provider IT staff, as well as the capability of the Service Provider to retain this knowledge and skill through employee retention.

As evidenced by the preceding resource-based and capabilities literature, these human resource variables of employee skills, knowledge and retention can have an impact on the possibility of loss in an offshore outsourcing relationship. If these assets are not present and are not leveraged to provide value to the firm, it increases the likelihood that the service provider will fail and a loss will occur[12]. This is the basis for Proposition 1b:

Proposition 1b: The quality of a service provider's human resource assets, taken as a part of their overall IT capabilities, will impact the offshore outsourcing risk for that service provider.

\subsection{Service provider cultural climate}

The service provider's cultural climate refers here to the cultural norms and social mores of service provider's nation and its employees, particularly collectivism and the ensuing level of respect for intellectual property ownership. Hofstede defines culture as "the collective programming of the mind which distinguishes members of one group from another[17]. Although specific "cultures" can vary across organizations of individuals as small as teams within corporations [18], certain aspects of human behavior are apparent across most citizens in any particular nation[19] . Culture variables which are similar across a national or ethnic level greatly impact the culture of a particular service provider, since the employee base of that service provider is primarily drawn from members of this particular national and/or ethnic culture. Although cultural differences among individuals exist at every possible level of analysis (e.g. team, organization, region, nation), the scope of this research focuses on risk at a service provider level. Thus, we choose to analyze service provider cultural variables as they relate to offshore outsourcing risk.

Proposition 2: The level of collectivism inherent in the service provider's culture, and the level of respect for intellectual property ownership inherent in that level of collectivism, will impact the offshore outsourcing risk for that service provider.

\subsection{Service recipient risk mitigation strategies}

Certain strategies that are put in place by the service recipient organization have the potential to moderate the impact of service provider's IT capabilities and cultural climate on offshore outsourcing risk. These practices include any other corporate policies that, while not specifically aiming to protect assets, may be used for that purpose as well. Service recipient risk mitigation strategies that could moderate these impacts include establishing intelligence and strong contract construction. These strategies may moderate the service recipient's vulnerability to the affects of the capabilities and cultural variables of the service provider [2]. Thus, with the probability of loss being reduced by the usage of these strategies, the overall risk would be lowered.

This brings us to the following proposition:

Proposition 3a: The contract put in place by an offshore outsourcing service recipient will 
moderate the impact of an offshore outsourcing service provider's cultural climate on the offshore outsourcing risk that may be attendant in dealing with this particular service provider.

Culture-driven behavior, in an offshore outsourcing relationship, takes place after the relationship has already been established. Thus it is temporally possible to direct and/or change this risk factor. The service provider's IT capabilities, however, exist prior to the relationship formation. Although it is possible to change aspects of these capabilities through the updating of technology and addition or subtraction of employees, this would require significant time, effort and capital. Perhaps the most realistic control mechanism for the risks posed through the service provider's infrastructure is for the service recipient to thoroughly familiarize itself with the service provider's current capabilities climate before the relationship begins, so that it can prepare itself for any complications that may arise. This is known in the decision-making sciences as "intelligence" - the first step in the three-stage decision making model of intelligence, design and choice [20]. Thorough, on-site investigation of the facilities where work is to be done and their surrounding area are necessary to counteract properties of the service recipient that the service provider has no control over, such as communication network structure [2].

The service recipient's use of intelligence gathering mitigates the probability that a loss will occur through selection of service providers with appropriate levels of IT capabilities needed for the task to be outsourced. Taking the above discussion into consideration, the following proposition is put forth:

Proposition 3b: The pre-emptive investigation undertaken by an offshore outsourcing service recipient will moderate the impact of an offshore outsourcing service provider's capabilities on the offshore outsourcing risk that may be attendant in dealing with this particular service provider.

\subsection{Service provider risk mitigation strategies}

The existence of poorly developed infrastructures and cultural environments that do not protect the rights of intellectual property ownership can greatly impact the risks of an offshore outsourcing relationship. However, service providers may already possess risk mitigation strategies that counteract some of the affects that capabilities and social variables can have on the risks for offshore outsourcing relationships.

These service provider policies can reduce the chance that the service recipient may experience a loss due to inadequacies in service provider capabilities, or due to cultural variables such as levels of collectivism inherent in the service provider organization. This leads to the fourth proposition in this research:

Proposition 4: A service provider's risk mitigation strategies will moderate the impact of an offshore outsourcing service provider's cultural climate on the offshore outsourcing risk that may be attendant in dealing with this particular service provider.

\section{Conclusion}

The aim of this research is to expose determinants of the offshore outsourcing risks inherent in any offshore outsourcing transaction. Through review of the literature, several 
determinants were found that exist from the perspective of the service provider or vendor. These determinants included service provider IT capabilities and service provider cultural variables. Through a better understanding of the determinants, service recipients can further secure their offshore outsourcing partnerships against risk.

The first step in mitigating any of the service provider risks associated with offshore outsourcing risk is to understand the risk inherent. Many of these risks are caused because the environment of the service provider, and thus the environment that the work will be taking place in, is vastly different from the environment of the service recipient. These differences need to be thoroughly investigated and understood prior to the selection of the service provider and the contracts being drawn up. This way, the service recipient will have a better understanding of the nature of the relationship they are about to enter, and thus will stand less of a chance for being blindsided by any potential hazards that they were unaware of.

Also, this understanding will allow for the service provider and service recipient to mitigate or reverse risk factors that they have control over. Understanding these service provider variables will also aid the service recipients in drawing up contracts and instituting other forms of controls (such as reward schedules, penalties, etc) that can mitigate some of the vendor risks that cannot be controlled by the service provider or service recipient. Cultural or social norms of the service provider's employee base that run counter to the values of the service recipient can be addressed through clauses in the contract dealing with legal vs. illegal sharing of corporate data, work being done in the office only vs. being taken home, and other measures to combat cultural norms that may be hazardous to intellectual property rights.

This research also brings to light many areas for future study concerning the risks of offshore outsourcing relationships. While the cost of risk mitigation may in itself not be a determinant of the overall risk of a particular relationship, transaction cost can and does play a significant role in any risky situation, particularly one which has the potential to be as expensive as an offshore outsourcing partnership.The effects of transaction cost theories on offshore outsourcing risks offer a potentially interesting avenue of future research, especially considering the fact that many offshore outsourcing projects are undertaken specifically to reduce costs in the organization. It would be interesting to see if the costs saved by sending work overseas were proportionally larger than the costs involved in adequately mitigating the risks inherent in offshore outsourcing transactions.

Another area of research involves determinants of offshore outsourcing risks relative to the degree of cultural difference between nations. This research looks at the variables that determine risks to offshore outsourcing. However, it would be interesting to look at the degree of difference in each of these determinants for the service provider and service recipient as the true determinant of offshore outsourcing risk. For example, the difference in cultural environments between two developing countries, or two countries in the same geopolitical region of the world, might be very small if a difference even existed; for those countries, cultural climate may not be a determinant of offshore outsourcing risk because the difference in cultural climates was very small.

However, for a developing country such as Indonesia, the difference in our cultural system with that of a developed country such as Canada could make the cultural climate a determining factor of offshore outsourcing risk. In researching this it may be found that the degree of difference in these variables is the true determinant, rather than the variables themselves.

\section{References}

[1] “Global IT Outsourcing Market 2014-2018,” Infinity Research Limited, Technavio, 2014. 
[2] M. Fitzgerald, "At Risk Offshore: Intellectual Property Protection: How to Write Safer Offshore Outsourcing Contracts," CIO Mag., 2003.

[3] R. B. Heeks, Software Strategies in Developing Countries. 1999.

[4] R. Kishore dan H. R. Rao, "A Relationship Perspective on IT Outsourcing," Commun. ACM, vol. 46, no. 12, hlm. 87-93, 2003.

[5] S. Ang dan D. W. Straub, "Production and Transaction Economies in IS Outsourcing: A Study of the US Banking Industry," MIS Q., vol. 22, no. 4, 1998.

[6] T. Kern, "The Gestalt of an Information Technology Outsourcing Relationship," dalam International Conference on Information Systems, Proceedings of the eighteenth international conference on Information Systems, Atlanta, GA, USA, 1997.

[7] A. L. Cavaye, "Transnational Information Systems - A Challenge for technical and General Managers," dalam ACM SIGCPR conference on Computer personnel research, San Francisco, CA: United States, 1997.

[8] M. C. Lacity dan L. P. Willcocks, "An Empirical Investigation of Information Technology Sourcing Practices: Lessons from Experience,” MIS Q., vol. 22, no. 3, 1998.

[9] M. Swinarski dan R. Kishore, "Impact of Organizational Capabilities on ITS Service Provider Performance," dalam Second International Conference on Outsourcing of Information Services (ICOIS, Bayreuth, Germany, 2001.

[10] R. Sabherwal, "The Role of Trust in IS Outsourced Development Projects," Commun. ACM, vol. 42, no. 2, hlm. 80-86, 1999.

[11] N. Khan dan W. L. Currie, "Developing a Model for Offshore Outsourcing," Ninth Am. Conf. Inf. Syst. Cross-Cult. Res., 2003.

[12] B. Aubert dan S. Rivard, Managing IT Outsourcing Risk: Lessons Learned. Scientific Series, Cirano Inc, 2001.

[13] J. Jia dan J. S. Dyer, “A Standard Measure or Risk and Risk Value Models,” Manag. Sci., vol. 42, no. 12, hlm. 1691-1705, 1996.

[14] B. S. Silverman, "Technological Resources and the Direction of Corporate Diversification: Toward an Integration of Resouce-based View and Transaction," Cost Econ. Manag. Sci., vol. 45, no. 8, hlm. 1109-1124, 1999.

[15] R. W. Coff, "The Resource Based View and Stakeholder Bargaining Power," Organ. Sci., vol. 10, no. 2, hlm. 119-133, 1999.

[16] D. C. . E. A. Galunic, "From Security to Mobility: Generalized Investments in Human Capital and Agent," Commit. Organ. Sci., vol. 11, no. 1, hlm. 1-20, 2000.

[17] G. Hofstede, Empirical Models of Cultural Differences. Contemporary issues in crosscultural psychology. Drenth. Amsterdam, Netherlands, 1991.

[18] K. R. Lenartowicz, A framework for Culture Assesment. 1999.

[19] P. M. Doney, J. P. Cannon, dan M. R. Mullen, "Understanding the Influence of National Culture on the Development of Trust," Acad. Manage. J., vol. 23, no. 3, hlm. 601-620, 1998.

[20] H. A. Simon, "On How To Decide What To Do. The Bell Journal of Economics (in Papers in Honor of Herbert A," Simon, vol. 9, no. 2, hlm. 494-507, 1978. 


